Tropical Journal of Pharmaceutical Research July 2017; 16 (7): 1663-1674

ISSN: $1596-5996$ (print); 1596-9827 (electronic)

(C) Pharmacotherapy Group, Faculty of Pharmacy, University of Benin, Benin City, 300001 Nigeria.

All rights reserved.

Available online at http://www.tjpr.org

Original Research Article

http://dx.doi.org/10.4314/tjpr.v16i7.27

\title{
Synthesis and characterisation of doxorubicin-loaded functionalised cobalt ferrite nanoparticles and their in vitro anti-tumour activity under an AC-magnetic field
}

\author{
Muhammad Waheed Mushtaq ${ }^{1,2 \star}$, Farah Kanwal ${ }^{2}$, Atif Islam ${ }^{3}$, Khalil Ahmed ${ }^{2}$, \\ Zia-ul-Haq ${ }^{2}$, Tahir Jamil ${ }^{3}$, Muhammad Imran ${ }^{2}$, Syed Mustansar Abbas ${ }^{4}$, \\ Qingrong Huang ${ }^{1}$ \\ ${ }^{1}$ Food Science Department, Rutgers, The State University of New Jersey 08901, USA, ${ }^{2}$ Institute of Chemistry, ${ }^{3}$ Department of \\ Polymer Engineering and Technology, University of the Punjab, Lahore-54590, Pakistan, ${ }^{4}$ Department of Energy and Materials \\ Engineering, Dongguk University, 30, Pildong-ro, 1-gil, Jung-gu, Seoul 100-715, Republic of Korea
}

*For correspondence: Email: waheedjaami@gmail.com; Tel: +92-03045578484

Sent for review: 22 November 2016

Revised accepted: 5 June 2017

\begin{abstract}
Purpose: To synthesise and evaluate the anti-tumour properties of doxorubicin-loaded xanthan gumfunctionalised cobalt ferrite nanoparticles ( $\mathrm{CoFe}_{2} \mathrm{O}_{4}$.NPs@XG-Doxo) under an AC-magnetic field.

Methods: Multidimensional magnetic cobalt ferrite $\left(\mathrm{CoFe}_{2} \mathrm{O}_{4}\right)$ nanoparticles (NPs) were synthesised by a co-precipitation method. The synthesised cobalt ferrite nanoparticles (CFNPS) were functionalised with xanthine gum (XG) and subsequently characterised by Fourier transform-infrared spectroscopy (FT-IR), thermogravimetric analysis (TGA) and contact angle studies. Vibrating sample magnetometry (VSM) was used for magnetic measurements of the native and XG-coated CFNPs. The microstructural morphology of the uncoated and XG-coated CFNPS was established using scanning electron microscopy (SEM), atomic force microscopy (AFM) and dynamic light scattering (DLS) studies. Finally, the doxorubicin release profile of the drug-loaded functionalised CFNPs was evaluated using an oscillating magnetic field (OMF) apparatus in the presence of an externally applied magnetic field.

Results: XG coating decreased the contact angle of the native CFNPs from $92^{\circ}$ to $40^{\circ}$, which indicates that it modified the CFNP surface from hydrophobic to hydrophilic. VSM analysis demonstrated that $\mathrm{CoFe}_{2} \mathrm{O}_{4} . \mathrm{NPs} @ X G$ also retained the magnetic characteristics of the bare cobalt ferrite nanocrystals, endorsing its application as a promising magnetic nanovector (MNV). The synthesised $\mathrm{CoFe}_{2} \mathrm{O}_{4} . \mathrm{NPs} @ X G-D o x o$ exhibited significantly higher controlled discharge of doxorubicin at acidic $\mathrm{pH}$ (5.0) than at neutral $\mathrm{pH}$ (7.4). In vitro analysis revealed the remarkable lower systematic toxicity of XGcoated $\mathrm{CoFe}_{2} \mathrm{O}_{4} . \mathrm{NPs}$ compared with uncoated CFNPs against Chinese hamster ovary (CHO) and Huh7 cell lines.
\end{abstract}

Conclusion: These results indicate that XG-coated CFNPs are a biocompatible MNV for doxorubicin.

Keywords: Cobalt ferrite, Cytotoxicity, Drug delivery, Nanoparticles, Xanthan gum

Tropical Journal of Pharmaceutical Research is indexed by Science Citation Index (SciSearch), Scopus, International Pharmaceutical Abstract, Chemical Abstracts, Embase, Index Copernicus, EBSCO, African Index Medicus, JournalSeek, Journal Citation Reports/Science Edition, Directory of Open Access Journals (DOAJ), African Journal Online, Bioline International, Open-J-Gate and Pharmacy Abstracts

\section{INTRODUCTION}

Various nanosystems have been proposed to increase their implementation in several biological fields, such as cancer therapy, pharmaceuticals and tissue engineering [1]. In particular, spinel ferrites $\left(\mathrm{MFe}_{2} \mathrm{O}_{4}, \mathrm{M}=\mathrm{Fe}^{+2}\right.$, $\mathrm{Zn}^{+2}, \mathrm{Mn}^{+2}, \mathrm{Co}^{+2}$ or $\mathrm{Ni}^{+2}$ ) are promising magnetic products for many biomedical applications. Cobalt ferrite nanoparticles (CFNPs) are suitable 
for magnetic resonance imaging (MRI) and targeted drug delivery (TDD) because of their tunable coercivity and excellent saturation magnetisation (Ms) [2]. There are various routes to prepare CFNPs, such as via combustion [3], microemulsions with oil-in-water micelles [4], reverse micelles [5], co-precipitation and calcination [6], sol-gels [7], microwaves [8] and forced hydrolysis in a polyol medium [9].

However, biomedical applications of native CFNPs are restricted because of their hydrophobic surface. Most of the plasma proteins are hydrophobic, which enables the rapid removal of hydrophobic nanostructures from the blood circulatory system through opsonisation [10]. Previously, nanoferrite functionalization was carried out by coating with proteins, polymers, surfactants, starch or chitosan [11]. We report herein the first investigation of encapsulating CFNPs with xanthan gum (XG), which is an anionic polysaccharide that coats the cationic surface of the NPs. The biocompatibility of XG suggests a broad range of applications in the biomedical arena [12].

Herein, we report the synthesis and characterisation of XG-coated CFNPs ( $\mathrm{CoFe} \mathrm{O}_{2}$.NPs@XG) to enhance application as a biocompatible magnetic nanovector (MNV) for targeted delivery of the anti-tumour drug doxorubicin (Doxo). The release of drug from $\mathrm{CoFe}_{2} \mathrm{O}_{4}$.NPs@XG-Doxo was determined in the absence as well as in the presence of an externally applied magnetic field (AMF). The cytocompatibility and toxicity of the naked and XG-coated ferrite NPs toward Chinese hamster ovary $(\mathrm{CHO})$ and Huh7 cell lines are also reported.

\section{EXPERIMENTAL}

\section{Materials}

Cobalt (II) chloride hexahydrate $\left(\mathrm{CoCl}_{2} \cdot 6 \mathrm{H}_{2} \mathrm{O}\right.$; Alfa Aesar, $98 \%$ purity), iron (III) chloride hexahydrate $\left(\mathrm{FeCl}_{3} \cdot 6 \mathrm{H}_{2} \mathrm{O}\right.$; Sigma-Aldrich, ACS reagent grade, $97 \%$ purity), potassium hydroxide $(\mathrm{KOH}$; Alfa Aesar, $98 \%$ purity), ethanol $\left(\mathrm{C}_{2} \mathrm{H}_{5} \mathrm{OH}\right.$; Sigma-Aldrich) and doxorubicin hydrochloride (Sigma-Aldrich) were used as received. Double-distilled deionised water was used as solvent.

\section{Synthesis of the CFNPs}

The CFNPs were synthesised using a previously reported method with minor modifications [13]. Briefly, aqueous solutions of ferric chloride (0.4 $\mathrm{M}, 25 \mathrm{~mL})$ and cobalt chloride $(0.2 \mathrm{M}, 25 \mathrm{~mL})$ were mixed and stirred in a three-necked flask at $\mathrm{pH}$ 1.34. Precipitation occurred immediately as 3 $\mathrm{M} \mathrm{KOH}$ solution was slowly added drop-wise under an inert atmosphere of nitrogen gas. Then, the reaction temperature was increased to $85^{\circ} \mathrm{C}$ and stirring was maintained for $90 \mathrm{~min}$. The resulting dark black precipitate was decanted using a strong permanent magnet, washed multiple times with distilled water and finally oven-dried at $100{ }^{\circ} \mathrm{C}$ for $12 \mathrm{~h}$. The synthesised cobalt ferrite nanocrystals were dialysed for $8 \mathrm{~h}$ in $100 \mathrm{~mL}$ of $0.02 \mathrm{M} \mathrm{HNO}_{3}$ solution to form a cationic charge over the surface, dried and stored at $4{ }^{\circ} \mathrm{C}$ for further functionalization.

\section{Synthesis of MNV (CoFe $\mathrm{O}_{4} \cdot \mathrm{NPs@XG)}$}

XG-coated CFNPs ( $\mathrm{CoFe}_{2} \mathrm{O}_{4}$.NPs@XG) were prepared by dispersing the dialysed cobalt ferrite nanocrystals in distilled water, mixing with $X G$ at a $1: 2$ ratio and stirring for $24 \mathrm{~h}$. The supernatant layer was discarded and the resulting dark brown coated cobalt ferrite nanocrystals were washed with distilled water and finally freeze-dried for further studies.

\section{In vitro drug loading and release studies}

The prepared MNV ( $\left.\mathrm{CoFe}_{2} \mathrm{O}_{4} \cdot \mathrm{NPs} @ X \mathrm{XG}\right)$ was loaded with Doxo by dissolving $10 \mathrm{mg}$ of dried $\mathrm{CoFe}_{2} \mathrm{O}_{4}$.NPs@XG in $25 \mathrm{~mL}$ of a drug solution $(0.2 \mathrm{mg} / \mathrm{mL})$ at room temperature and gently stirring for 2 days in the dark. The drug solution was prepared in phosphate-buffered solution (PBS) at $\mathrm{pH}$ 7.4. Thereafter, the drug-loaded magnetic nanoassembly, $\mathrm{CoFe}_{2} \mathrm{O}_{4}$.NPs@XGDoxo, was separated using a magnet, washed several times with PBS and finally freeze-dried. The supernatant and washed solutions were collected and analysed to determine the unloaded drug concentration by UV-visible (UVVis) spectroscopy at a wavelength of $481 \mathrm{~nm}$. The drug loading efficiency (L) was calculated using Eq 1.

$L(\%)=\frac{\omega-c}{\omega} \times 100$

where $C_{0}$ is the total amount of the added drug and $C$ is the unencapsulated amount of drug.

To determine the drug release profile, $6 \mathrm{mg}$ of the drug-loaded MNV ( $\mathrm{CoFe}_{2} \mathrm{O}_{4} \cdot \mathrm{NPs@XG}$ ) was sealed in a porous dialysis bag having a molecular weight cut-off (MWCO) of $10 \mathrm{kDa}$ (Millipore). Thereafter, the dialysis bag was suspended in $40 \mathrm{~mL}$ of sterile phosphatebuffered solution having $\mathrm{pH} 7.4$ and 5.0 separately at $37^{\circ} \mathrm{C}$ under gentle orbital shaking (120 rpm/min). At designated time intervals (1, 2, $4,6,8,10,12,24,36,48,20,24,36,48,60,72$, 
84, 96, 108 and $120 \mathrm{~h}$ ), $2 \mathrm{~mL}$ of dialysate was withdrawn from the dialysis bag to determine the released drug concentration. The withdrawn volumes of dialysate were returned to the release medium to reconstitute the original volume of PBS. In a similar fashion, the drug release experiment was repeated when the drug release system was placed in a $40-\mathrm{mL}$ glass tube in the presence of an external oscillating magnetic field (OMF) (ca. $1000 \mathrm{Oe}$ ) generated by a custommade instrument called a Teslamate. This device (Figure 1) consisted of 96 turns of a $76.5-\mathrm{mm}$ length of $0.8-\mathrm{mm}$-diameter copper wire that operated over a frequency of $1-500 \mathrm{kHz}$ at a current of 1-3 amperes and a magnetic flux density of $0-100 \mathrm{mG}$.

\section{Cell cultures}

The $\mathrm{CHO}$ and Huh7 cell lines were provided by the Centre of Excellence and Molecular Biology (CEMB), Lahore, Pakistan. To obtain culture growth, the cell lines were maintained in Dulbecco's modified Eagle's medium (DMEM) supplemented with $10 \%$ foetal bovine serum (FBS) and incubated at $37^{\circ} \mathrm{C}$ under a humidified atmosphere containing $5 \% \mathrm{CO}_{2}$. The cells lines were routinely harvested by adding $0.25 \%$ trypsin-ethylenediaminetetraacetic acid (EDTA) solution.

\section{Cytotoxicity of the MNV (CoFe $\left.\mathrm{O}_{4} \cdot \mathrm{NP} @ X G\right)$}

To analyse the in vitro cytotoxicity of the bare and coated cobalt ferrite NPs against $\mathrm{CHO}$ and Huh7, cells were harvested in 96-well plates at a density of 10,000 cells per well. Different concentrations of native $\mathrm{CoFe}_{2} \mathrm{O}_{4}$. NPs and $\mathrm{CoFe}_{2} \mathrm{O}_{4} . \mathrm{NPs} @ X \mathrm{XG}(0-2.0 \mathrm{mg} / \mathrm{mL})$ were added to each well, in duplicate. Thereafter, the culture plate was incubated at $37^{\circ} \mathrm{C}$ in humidified air containing $5 \% \mathrm{CO}_{2}$ for $48 \mathrm{~h}$. After culturing sufficient cells, the medium in all wells was exchanged with fresh medium. Finally, the standard MTT (3-(4,5-dimethylthiazol-2-yl)-2,5diphenyltetrazolium bromide) assay was used to measure the cell viability relative to that of the control untreated cells.

\section{In vitro cytotoxicity of the magnetic nanoassembly (CoFe $\mathrm{O}_{4} \cdot \mathrm{NPs@XG-Doxo)}$}

The in vitro cytotoxicity of the drug-loaded magnetic nanoassembly, $\mathrm{CoFe}_{2} \mathrm{O}_{4} \cdot \mathrm{NPs} @ X G-$ Doxo, was tested against the Huh7 cell line by MTT assay. Briefly, $1 \times 10^{4}$ cells/well were harvested in a 96-well plate and incubated at 37 ${ }^{\circ} \mathrm{C}$ with humidified air containing $5 \% \mathrm{CO}_{2}$ for 24 h. Then, different concentrations $(0-0.20 \mathrm{mg} / \mathrm{mL})$ of the drug-loaded magnetic nanoassembly were added to each well medium, in triplicate, and incubated in $5 \% \mathrm{CO}_{2}$ humidified air at $37^{\circ} \mathrm{C}$ for $24 \mathrm{~h}$ to determine cell viability.

\section{UV-visible spectroscopy}

The UV-vis spectra of the pure cobalt ferrite NPs were recorded in the range of 100-600 nm using a spectrometer (model UV2600; Shimadzu, Japan). The drug loading and release profile was also obtained with the same instrument at $481 \mathrm{~nm}$.

\section{Fourier transform-infrared (FT-IR) spectroscopy}

The FT-IR spectra of the cobalt ferrite NPs and its nanocomposites were recorded on a spectrophotometer (model 983; Perkin-Elmer, USA) using the $\mathrm{KBr}$ technique in the range of $400-4,000 \mathrm{~cm}^{-1}$.

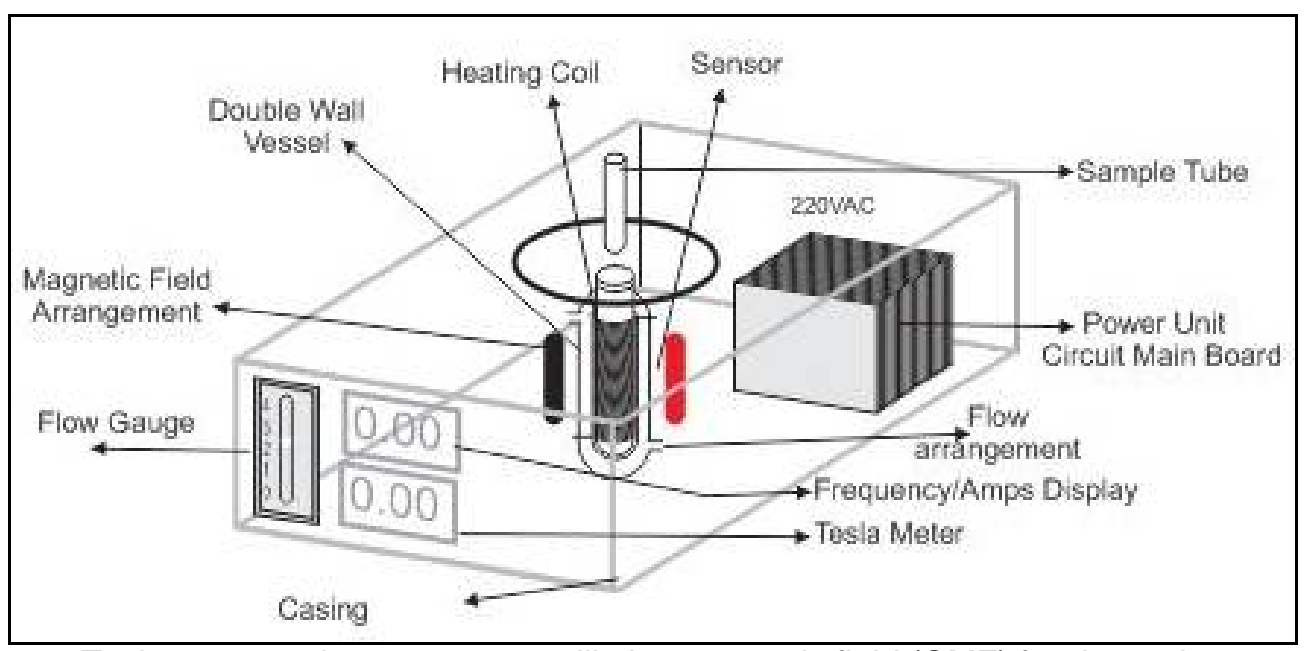

Figure 1: Teslamate used to generate oscillating magnetic field (OMF) for drug release studies 


\section{Thermogravimetric analysis (TGA)}

The thermal properties of the native cobalt ferrite NPs and the weight percentage of XG coated on the NPs were determined by TGA (model TGA50; Shimadzu, Japan) over the range of $20-800$ ${ }^{\circ} \mathrm{C}$.

\section{Contact angle measurements}

The contact angles of uncoated and XG-coated cobalt ferrite NPs were measured using a contact angle meter with the sessile drop method (model HO-ED-M-01, Holmarc Opto-Mechatronics, India).

\section{X-ray diffraction (XRD) studies}

XRD patterns were measured with a diffractometer (model 6000; Shimadzu, Japan) in the $2 \theta$ range of $5-70^{\circ}$ using Ni-filtered $\mathrm{Cu}-\mathrm{K} \alpha$ radiation. The crystallite size was determined from the broad diffraction plane (311) using the Debye-Scherer equation (Eq 2) [14]:

$\mathrm{D}=\frac{\pi \mathrm{R} A}{\beta \cos \theta}$

where $k$ is a constant (0.9), $\beta$ is the full-width at half-maximum (FWHM) of the high-intensity diffraction peak corresponding to the (311) plane, $\lambda$ is the wavelength of the $\mathrm{Cu} \mathrm{Ka}$ radiation (1.54 $\AA$ ) and $\theta$ is the Bragg angle.

\section{Vibrating sample magnetometry (VSM)}

The magnetic potential of coated and uncoated $\mathrm{CoFe}_{2} \mathrm{O}_{4}$.NPs was evaluated using a vibrating sample magnetometer (model 7404; Lake Shore Cryotronics, USA) at $300 \mathrm{~K}$ at an AMF ranging from -15 to $15 \mathrm{KOe}$.

\section{Microstructural analysis}

The microstructures of prepared samples were studied by scanning electron microscopy (SEM; model TM-1000; Hitachi, Japan). Atomic force microscopy (AFM; Park NX10, Korea) was used to measure the size of native and coated ferrite particles dispersed in hexane. The hydrodynamic diameter and polydispersity index (PDI) of a sample was measured by dynamic light scattering (DLS; Zetasizer Nano S; Malvern, UK).

\section{RESULTS}

\section{UV-vis spectra}

The successful synthesis of the cobalt ferrite NPs by co-precipitation was initially confirmed by UV-
Vis spectroscopy. The nanoferrite spectra displayed a characteristic shoulder band in the range of $330-500 \mathrm{~nm}$ that was attributed to their synthesis [15] (Figure 2).

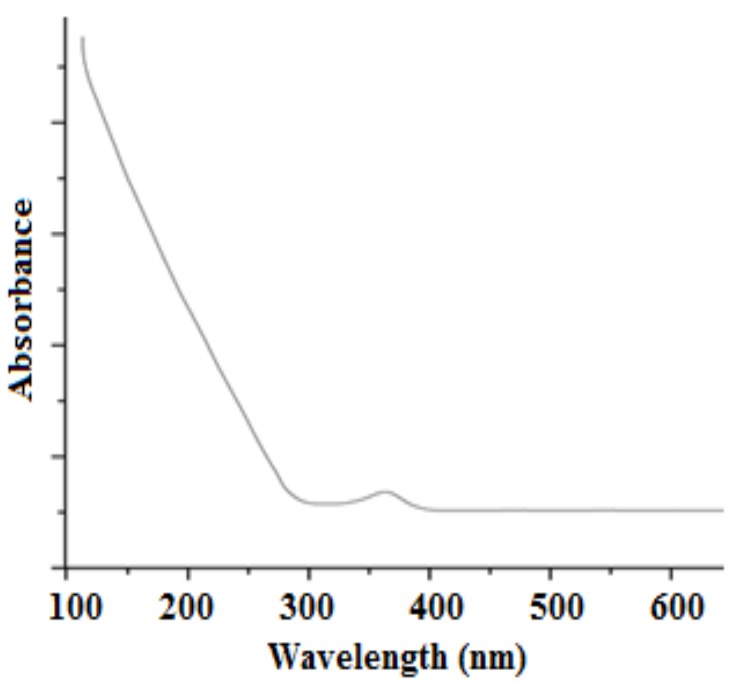

Figure 2: UV-visible spectrum of native cobalt ferrite NPs $\left(\mathrm{CoFe}_{2} \mathrm{O}_{4}\right.$.NPs)

\section{Attenuated total reflectance (ATR) FT-IR spectra}

The CFNPs and their XG-coated derivative

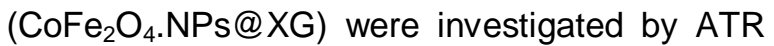
FT-IR spectroscopy. Figure 3 shows the spectra of the uncoated and coated CFNPs. The characteristic spinel-phase peaks of native cobalt ferrite NPs observed at 610 and $492 \mathrm{~cm}^{-1}$ were attributed to the intrinsic vibration of $(\mathrm{M}-\mathrm{O})_{\text {th }}$ and $(\mathrm{M}-\mathrm{O})_{\text {oh }}$ sites, respectively [16]. The splitting of the low-frequency band at the octahedral (B) site revealed the presence of different metal ions including $\mathrm{Fe}^{3+}, \mathrm{Fe}^{2+}$ and $\mathrm{Co}^{2+}$. The broad absorption band at $3350-3500 \mathrm{~cm}^{-1}$ was assigned to the stretching vibration of the $-\mathrm{OH}$ group. Figure $3 b$ shows the presence of the ferrite spinel lattice band at $400-600 \mathrm{~cm}^{-1}$, which confirmed the coating of XG over the ferrite NPs. The additional bands at 1447 and $1072 \mathrm{~cm}^{-1}$ correspond to the $\mathrm{M}-\mathrm{O}-\mathrm{C}$ linkage $(\mathrm{M}=\mathrm{Co}, \mathrm{Fe})$ [17]. Various quinone and ketone carbonyl peaks confirmed the loading of Doxo onto the coated CFNPs (Figure 3c). The splitting of the 29503250 and $1547 \mathrm{~cm}^{-1}$ peaks correspond to the $\mathrm{N}-\mathrm{H}$ stretching and $\mathrm{N}-\mathrm{H}$ bending vibrations, respectively, of the secondary amide group. In brief, the FT-IR spectrum of the loaded drug (Figure $3 c$ ) revealed the drug adsorption in two ways: first, by partial interaction between the $\mathrm{XG}$ carboxylate $\left(\mathrm{COO}^{-}\right)$and amine $\left(-\mathrm{NH}_{2}\right)$ groups of the drug via amide formation and, second, by the $-\mathrm{OH}$ vibrational bands. 
Table 1: Significant infrared stretching frequencies

\begin{tabular}{|c|c|c|}
\hline Sample & IR region or band $\left(\mathrm{cm}^{-1}\right)$ & Characteristic vibration* \\
\hline \multirow[t]{3}{*}{$\mathrm{CoFe}_{2} \mathrm{O}_{4} \cdot \mathrm{NPs}$} & 3480 & $v_{s}(\mathrm{O}-\mathrm{H})$ \\
\hline & 610 & $v_{3}\left(\mathrm{CoFe}_{2} \mathrm{O}_{4}\right)$ th, $\mathrm{A}$-site \\
\hline & 492,438 & $v_{3}\left(\mathrm{CoFe}_{2} \mathrm{O}_{4}\right)_{2,} \mathrm{~B}$-site \\
\hline \multirow[t]{8}{*}{$\mathrm{CoFe}_{2} \mathrm{O}_{4} \cdot \mathrm{NPs} @ \mathrm{XG}$} & $3600-3000$ & $v_{\Omega}(\mathrm{O}-\mathrm{H})$ \\
\hline & 2930,2840 & $v_{a s}(\mathrm{C}-\mathrm{H})$ and $v_{s}(\mathrm{C}-\mathrm{H})$, xanthan gum \\
\hline & 1639 & $\delta(\mathrm{H}-\mathrm{O}-\mathrm{H})$, free or absorbed water \\
\hline & 1526 & $v_{a s}\left(\mathrm{OCO}^{-}\right)$, free carboxylic group \\
\hline & 1447,1072 & $v_{5}(\mathrm{M}-\mathrm{O}-\mathrm{C}), \mathrm{M}=\mathrm{Fe}, \mathrm{Co}$ \\
\hline & 1160 & acetal group, xanthan gum \\
\hline & 596 & $v_{s}\left(\mathrm{CoFe}_{2} \mathrm{O}_{4}\right)_{t b}, \mathrm{~A}$-site \\
\hline & 474,432 & $v_{8}\left(\mathrm{CoFe}_{2} \mathrm{O}_{4}\right)_{e h}$, B-site \\
\hline \multirow[t]{10}{*}{$\mathrm{CoFe}_{2} \mathrm{O}_{4} \cdot \mathrm{NPs} @ \mathrm{XG}-\mathrm{Dox}$} & $3560-3160$ & $v_{s}(\mathrm{O}-\mathrm{H})$, hydrogen-bonded \\
\hline & $3160-2300$ & $v_{a s}(C-H), v_{3}(C-H)$ \\
\hline & 2076 & $v_{5}(\mathrm{C}=\mathrm{O})$, ketone group \\
\hline & 1617 & $\delta(\mathrm{H}-\mathrm{O}-\mathrm{H})$, free or absorbed water \\
\hline & 1547 & $(\mathrm{~N}-\mathrm{H})$, secondary amide \\
\hline & 1117 & $(\mathrm{C}-\mathrm{O})$, tertiary alcohol \\
\hline & 1036 & $(\mathrm{C}-\mathrm{O})$, secondary alcohol \\
\hline & 872 & $-\mathrm{NH}_{2}$, primary amine \\
\hline & 584 & $v_{\Omega}\left(\mathrm{CoFe}_{2} \mathrm{O}_{4}\right) t b, \mathrm{~A}$-site \\
\hline & 470 & $v_{\mathrm{s}}\left(\mathrm{CoFe}_{2} \mathrm{O}_{4}\right)$ oh, B-site \\
\hline
\end{tabular}

$v_{y_{5}}$, symmetric stretching; $v_{a s}$, asymmetric stretching; $\delta$, scissoring vibration

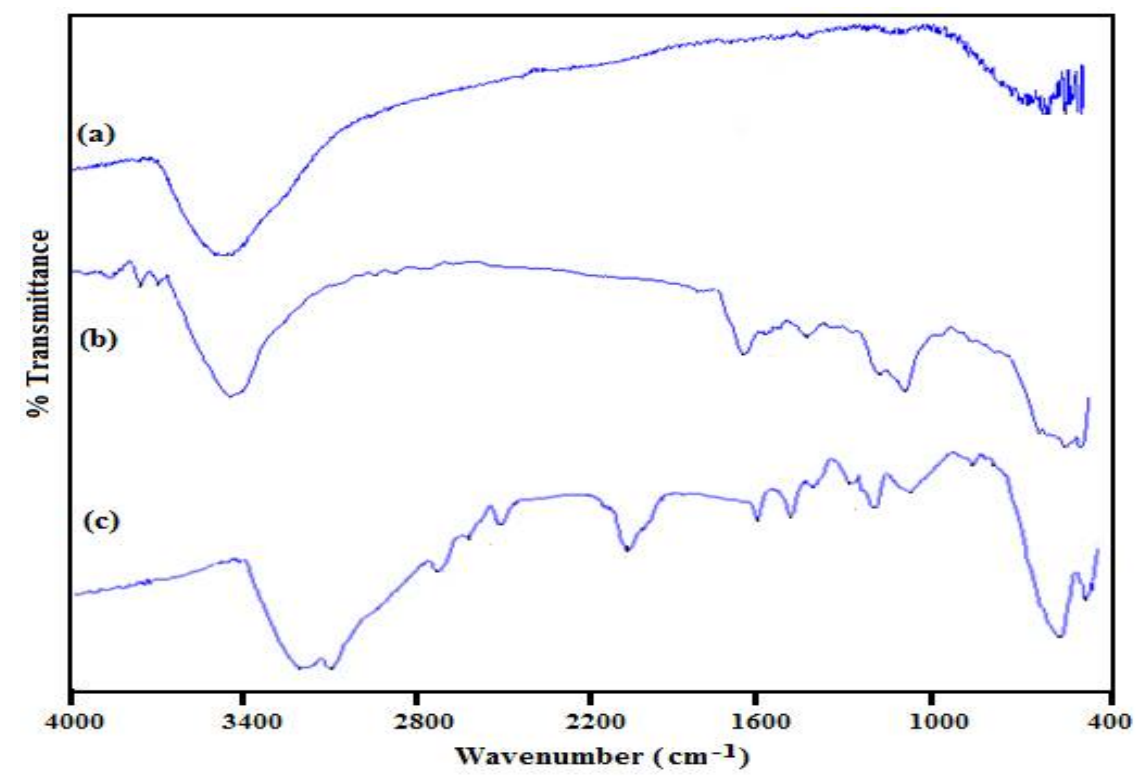

Figure 3: ATR-FTIR spectrums of (a) pure CFNPs; (b) xanthan gum coated ( $\left.\mathrm{CoFe}_{2} \mathrm{O}_{4} . \mathrm{NPs} @ X \mathrm{XG}\right)$; and (c) doxorubicin loaded cobalt ferrite NPs ( $\mathrm{CoFe}_{2} \mathrm{O}_{4}$.NPs@XG-Dox)

\section{Thermal characteristics}

Thermal analysis of the uncoated and coated CFNPs was performed from 25 to $800{ }^{\circ} \mathrm{C}$ to obtain quantitative evidence of the nanoferrite coating. The TGA curves of the pure and XGcoated ferrite NPs displayed different thermal behaviours (Figure 4). The percentage weight loss of the uncoated ferrite nanocrystals was just $3 \%$ over the range of $20-200{ }^{\circ} \mathrm{C}$. However, the XG-coated CFNPs exhibited a ca. $8 \%$ mass loss below $150^{\circ} \mathrm{C}$, which increased to ca. $16 \%$ from 150 to $380^{\circ} \mathrm{C}$.

\section{Contact angle}

The wettability and surface interactions of the coated and uncoated CFNPs with water were determined by contact angle measurements. CFNPs should be hydrophilic for biomedical applications. Figure 4 shows the sessile water droplet $(2 \mu \mathrm{L})$ contact angles over thick solid sample surfaces. The contact angles of the native and XG-coated ferrite NPs were $92.40^{\circ}$ and $39.90^{\circ}$, respectively (Figure $5(\mathrm{a}, \mathrm{b})$ ). 


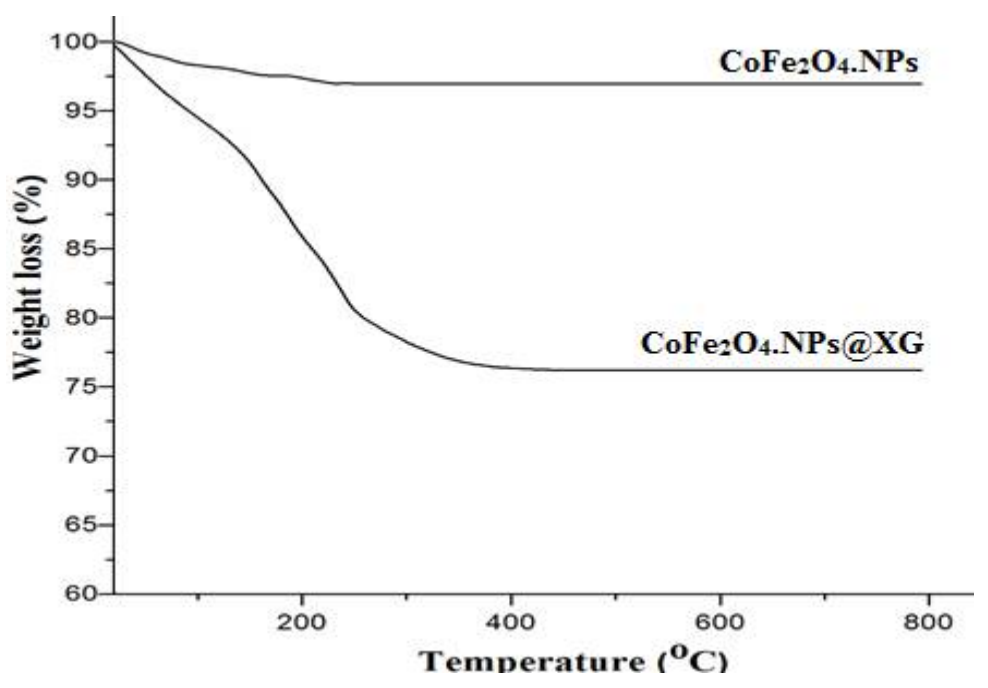

Figure 4: Thermogravimetric curves for native $\left(\mathrm{CoFe}_{2} \mathrm{O}_{4} \cdot \mathrm{NPs}\right)$ and xanthan gum coated cobalt ferrite nanoparticles ( $\left.\mathrm{CoFe}_{2} \mathrm{O}_{4} . \mathrm{NPs} @ X \mathrm{XG}\right)$

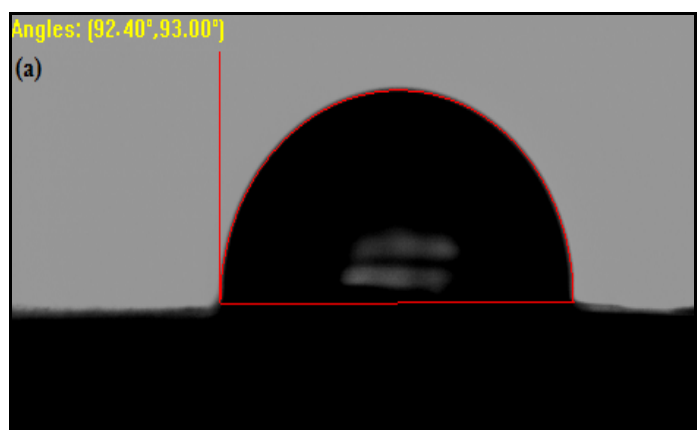

Figure 5: Contact angle images of (a) uncoated $\mathrm{CoFe}_{2} \mathrm{O}_{4} . \mathrm{NP}$ $\left(\mathrm{CoFe} \mathrm{O}_{4} . \mathrm{NPs} @ X \mathrm{XG}\right)$ for comparison of their wettability with water droplet

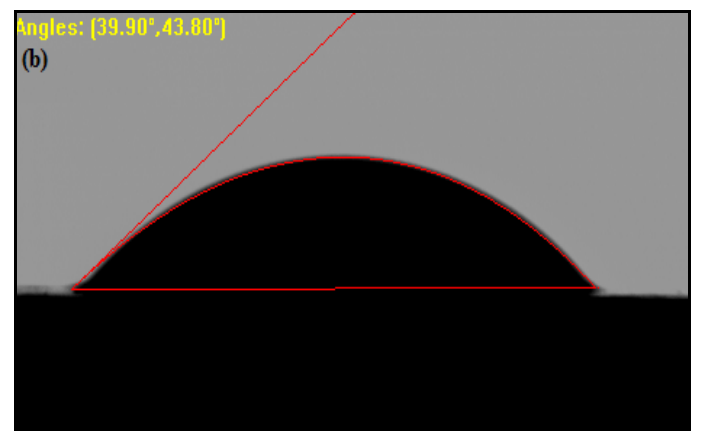

(b) XG-coated cobalt ferrite NPs

\section{XRD}

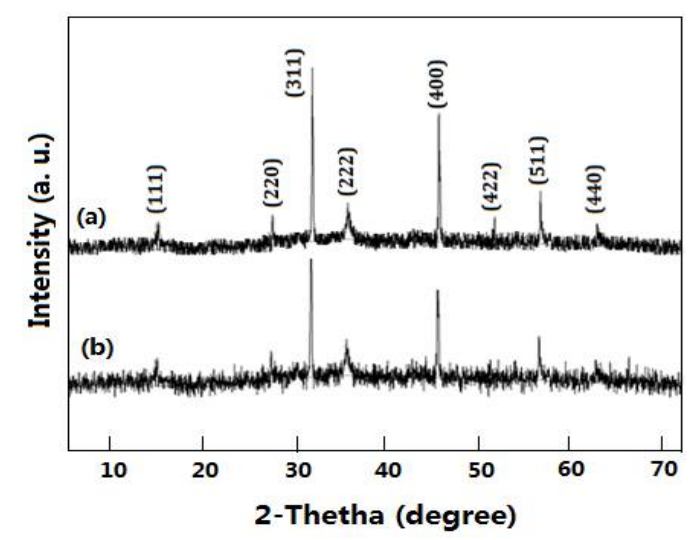

Figure 6: XRD patterns of (a) uncoated $\mathrm{CoFe}_{2} \mathrm{O}_{4}$.NPs and (b) xanthan gum-coated $\mathrm{CoFe}_{2} \mathrm{O}_{4} . \mathrm{NPs} @ X \mathrm{XG}$ (b)

Figure 6 shows the XRD patterns of the uncoated $\left(\mathrm{CoFe}_{2} \mathrm{O}_{4}\right.$.NPs $)$ and XG-coated ( $\mathrm{CoFe}_{2} \mathrm{O}_{4}$.NPs@XG) CFNPs. For the uncoated case, the (111), (220), (311), (222), (400), (422), (511) and (440) diffraction planes corresponded to angles of $18.29^{\circ}, 30.08^{\circ}, 35.44^{\circ}, 37.06^{\circ}$, $43.06^{\circ}, 53.45^{\circ}, 56.98^{\circ}$ and $62.59^{\circ}$, respectively. The indexed values of the uncoated CFNPs were in agreement with the Joint Committee on Powder Diffraction Standards (JCPDS) data card no. 22-1086 for the inverse spinel structure having a cubic geometry. The same characteristic XRD peaks were also observed for the XG-coated CFNPs (Figure 6 (b)), also indicating the single-phase spinel structure for the coated sample. The average crystal size (D) of the uncoated $\mathrm{CoFe}_{2} \mathrm{O}_{4}$.NPs was $18 \mathrm{~nm}$.

\section{Morphology}

SEM, AFM and DLS were used to investigate the microstructure of the uncoated and XG-coated CFNPs. SEM images (Figure $7(a, b)$ ) reveal the elongated, oval-shaped morphology of the native ferrite NPs. The average size of the native and coated CFNPs ranged from 20 to $60 \mathrm{~nm}$. Topographical images of the uncoated and coated $\mathrm{CoFe}_{2} \mathrm{O}_{4}$.NPs are shown in Figure $8(\mathrm{a}$, b). Furthermore, the 3-D AFM image (Figure 8c) confirmed the oval-shaped texture of the uncoated CFNPs, as previously noted [18]. DLS measurements (Figure 9) established a PDI of less than 0.16 and a nanosized range for all of the prepared samples [9]. 

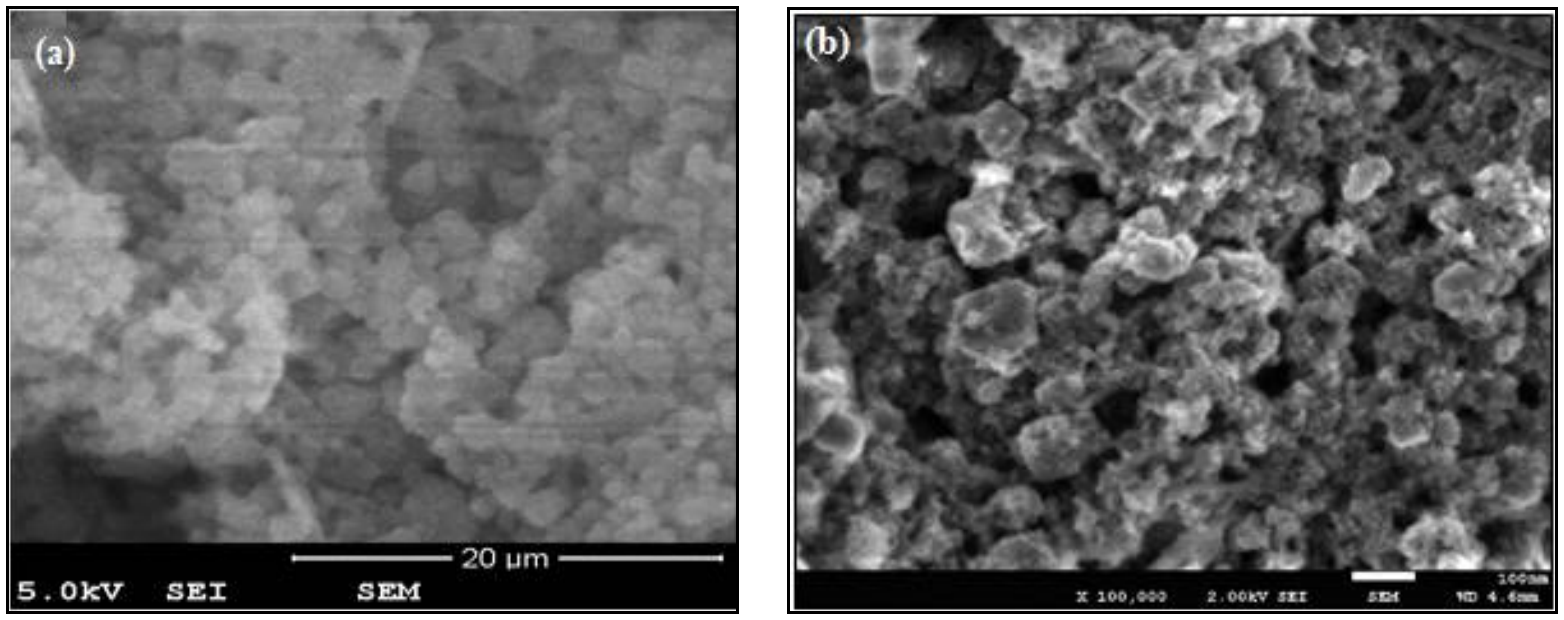

Figure 7: SEM images of uncoated (a); and XG-coated Cobalt ferrite NPs (b)
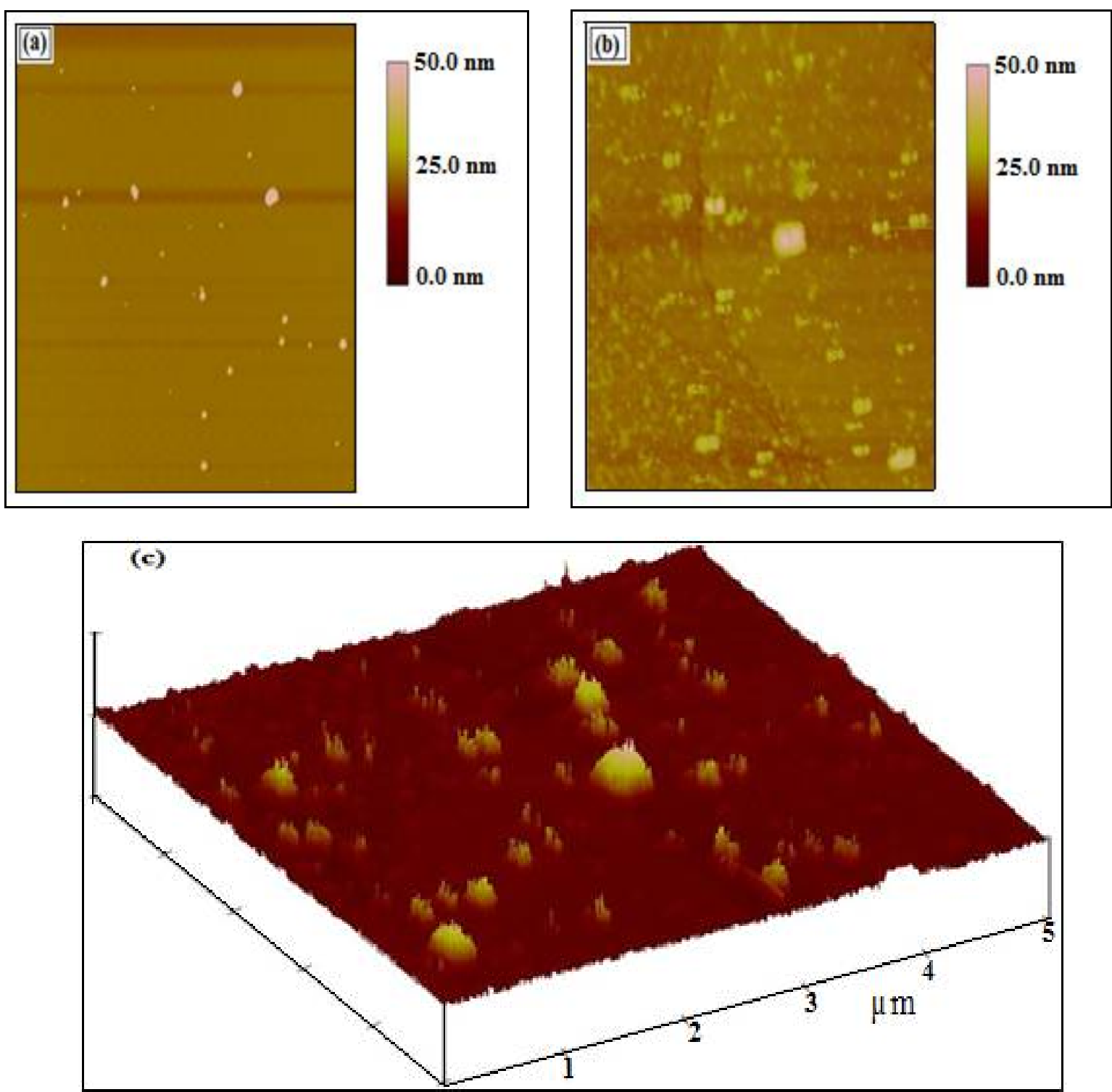

Figure 8: Topographical AFM images of (a) uncoated; (b) XG-coated Cobalt ferrite NPs; (c) 3D AFM image of native $\mathrm{CoFe}_{2} \mathrm{O}_{4}$.NPs 


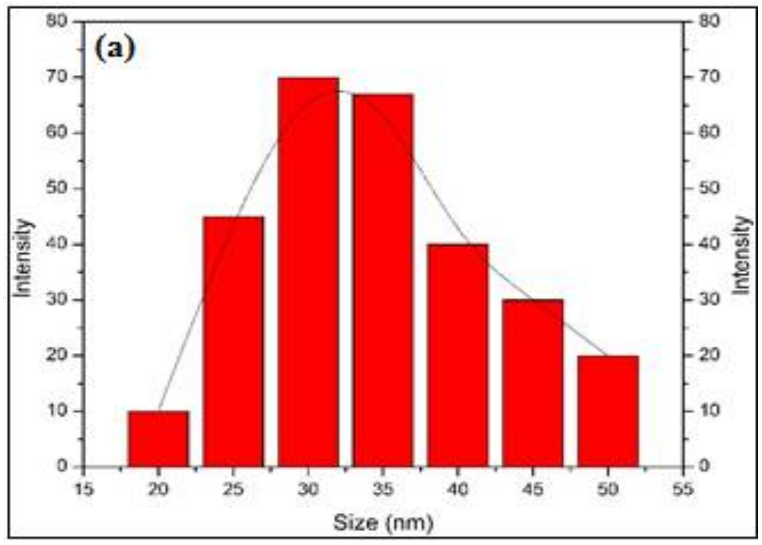

Figure 9: Size histogram images of (a) uncoated; measurements

\section{Magnetic properties}

The magnetic properties of the uncoated and XG-coated CFNPs were measured by VSM at room temperature. Figure 10 shows the magnetisation as a function of the applied field $(M-H$ curves) of the coated and uncoated CFNPs for magnetisation varying from -15 to 15 kOe. VSM study produced Ms values of 62.55 and $50.27 \mathrm{emu} / \mathrm{g}$ for the uncoated and coated CFNPs, respectively. A suspension of pure CFNPs showed a strong attraction toward a magnetic field (Figure 11).

\section{Drug release profile}

The anti-tumour drug release profile of the drugloaded MNV was determined in the absence and presence of an external AMF. The Doxo encapsulation efficiency of the

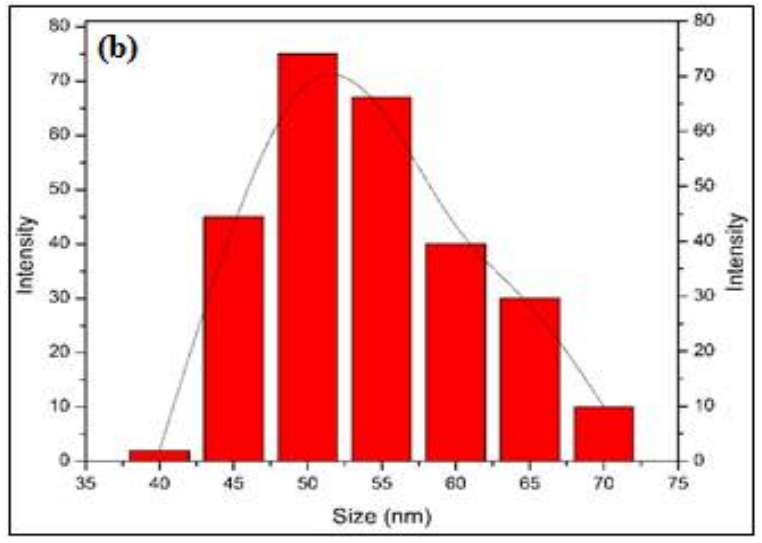

(b) XG-coated Cobalt ferrite NPs obtained from DLS

$\mathrm{CoFe}_{2} \mathrm{O}_{4} \cdot \mathrm{NPs} @ X \mathrm{XG} \mathrm{MNV}$ was ca. $83 \%$, which is greater than previously reported [19]. Wong et al. reported an average encapsulation efficiency of ca. $70 \%$ for Doxo on solid lipid nanoparticles (SLNs) [20]. The drug release behaviour of the MNV was studied for $120 \mathrm{~h}$ in phosphatebuffered saline $(0.1 \mathrm{M})$ at two different $\mathrm{pHs}(7.4$ and 5.0) at $37^{\circ} \mathrm{C}$ (Figure $\left.12(\mathrm{a}, \mathrm{b})\right)$. The $\mathrm{pH}$ of 7.4 corresponds to the normal environment of body tissue and blood, while $\mathrm{pH} 5.0$ is more appropriate for tumour-affected cells [21]. The drug-loaded MNV (CoFe $\mathrm{O}_{4}$.NPs@XG-Doxo) did not show a significant release of Doxo at neutral $\mathrm{pH} 7.4$ in the absence (13.5\%) as well as presence (32\%) of AMF after $120 \mathrm{~h}$. In contrast, at $\mathrm{pH} 5.0$, the discharge of drug was slow (ca. 15 $\%$ ) in the first $6 \mathrm{~h}$, which increased to $39 \%$ after $120 \mathrm{~h}$. However, an increased, controlled and regular release of drug up to $69 \%$ was observed in the presence of the external AMF after $120 \mathrm{~h}$.

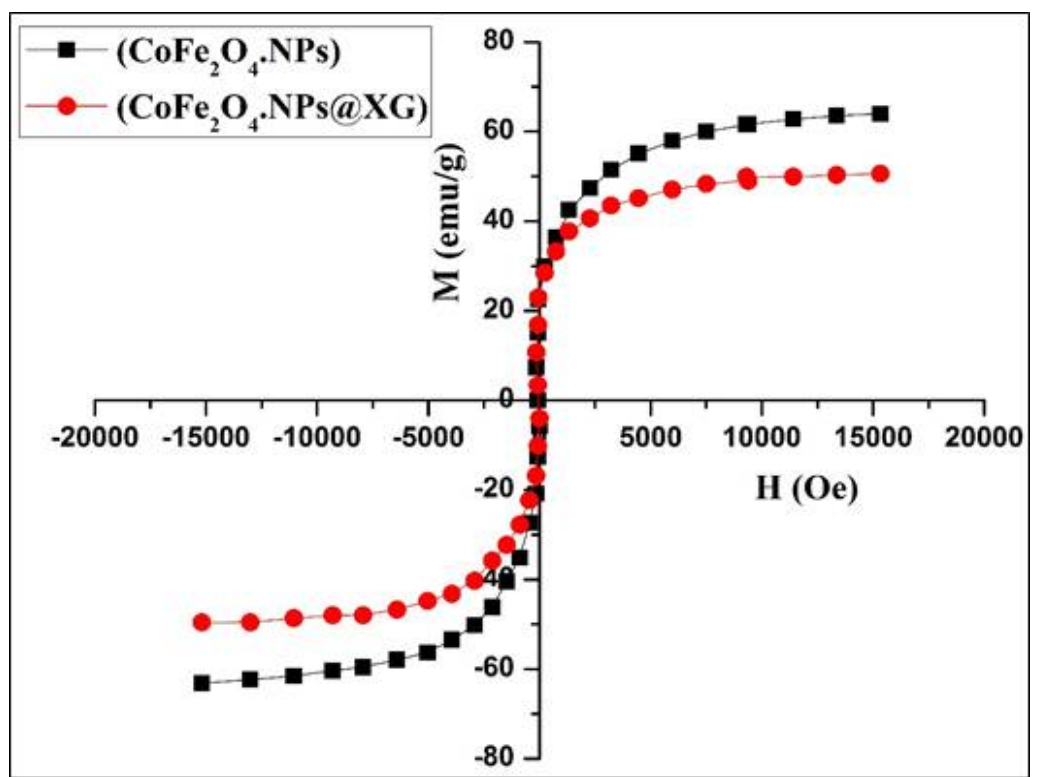

Figure 10: Vibrating sample magnetometer graphs of uncoated $\left(\mathrm{CoFe}_{2} \mathrm{O}_{4} . \mathrm{NPs}\right)$ and XG-coated Cobalt ferrite NPs $\left(\mathrm{CoFe}_{2} \mathrm{O}_{4} \cdot \mathrm{NPs} @ X \mathrm{XG}\right)$ 


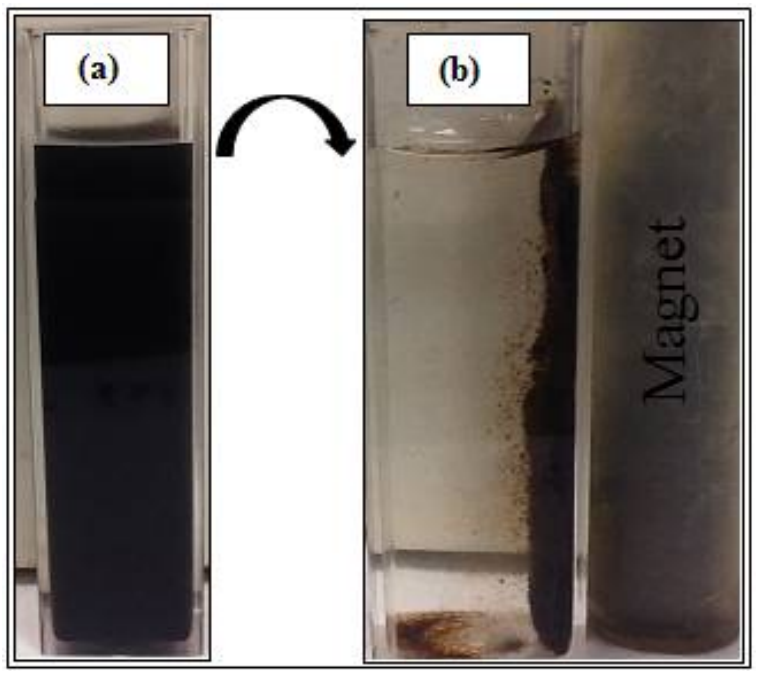

Figure 11: $\mathrm{CoFe}_{2} \mathrm{O}_{4}$.NPs suspension (a); which is exhibiting magnetic response towards a magnet (b)
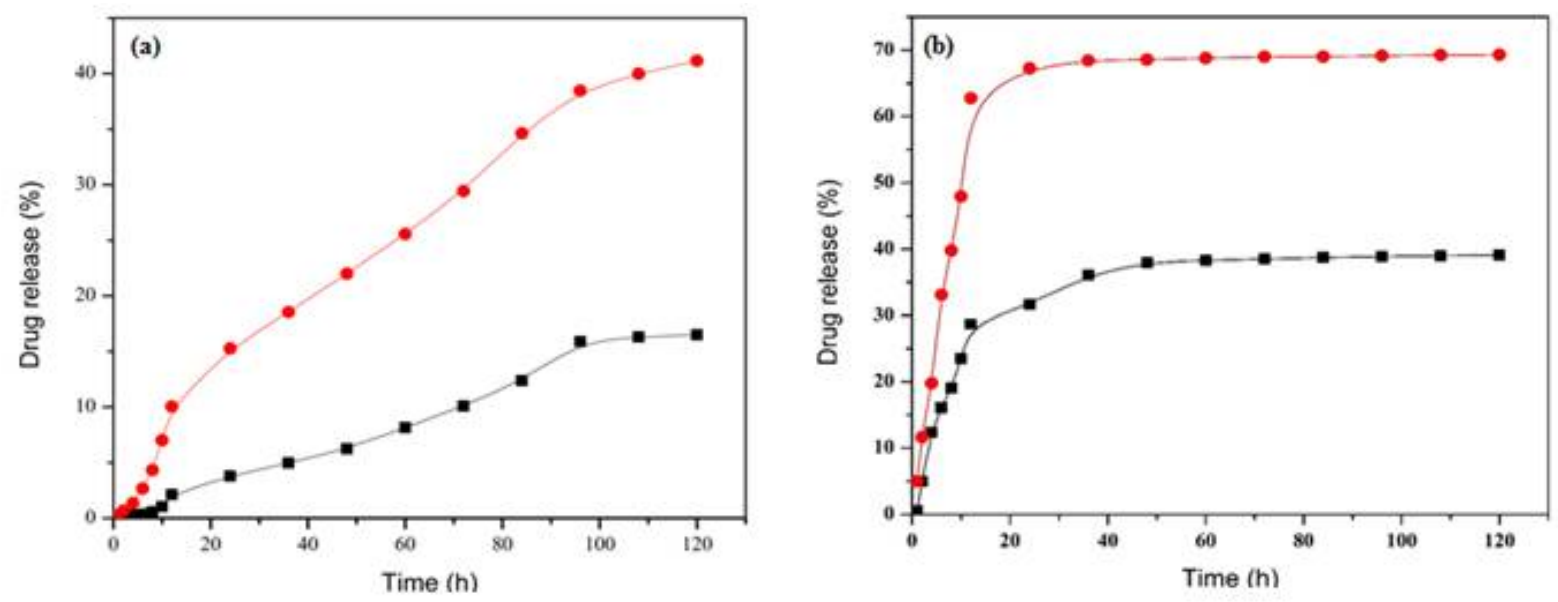

Figure 12: Drug release profile in the absence $(\mathbf{})$ and presence $(\bullet)$ of externally applied magnetic field (AMF) at (a) $\mathrm{pH} \sim 7.4$; (b) $\mathrm{pH} \sim 5.0$

\section{In vitro toxicity of $\mathrm{CoFe}_{2} \mathrm{O}_{4} \cdot \mathrm{NPs} @ \mathrm{XG}$}

The MTT assay against the $\mathrm{CHO}$ and Huh7 cell lines was used to establish the in vitro toxicity of the XG-coated ferrite NPs. Figure 13 exhibits the cell viability profiles of the $\mathrm{CHO}$ and Huh7 cells incubated at various concentrations (0-2.0 $\mathrm{mg} / \mathrm{mL}$ ) of MNV. After $48 \mathrm{~h}$ of dose exposure, cell viability exceeding $80 \%$, even at a high concentration $(1.6 \mathrm{mg} / \mathrm{mL})$, confirmed the biocompatibility of the $\mathrm{CoFe}_{2} \mathrm{O}_{4} \cdot \mathrm{NPs} @ X \mathrm{XG}$. This is likely because $X G$ is a food-grade polysaccharide whose degradation products are not toxic to the exposed cells.

\section{Pharmacological activity of $\mathrm{CoFe}_{2} \mathrm{O}_{4}$.NPs@XG-Doxo}

A $0-0.18 \mathrm{mg} / \mathrm{mL}$ dose of the drug-loaded MNA (CoFe $\mathrm{O}_{4}$.NPs@XG-Doxo) was applied to Huh7 cells over $48 \mathrm{~h}$ of incubation to investigate its pharmacological activity. Figure 14 reveals the significant decrease in the percentage cell viability with increasing concentration of the magnetic nanoassembly. More than $50 \%$ of the cells were dead even at the low concentration of $0.16 \mathrm{mg} / \mathrm{mL}$. This marked decrease in cell viability was attributed to the anti-proliferative effect of the Doxo discharged from the MNA.

\section{DISCUSSION}

The UV-vis absorption band in the range of 330$500 \mathrm{~nm}$ was attributed to the homogenised electronic motion of the CFNPs. Generally, metal nanoparticles display a characteristic plasmon resonance band in their UV-vis absorbance spectra due to the collective resonance of their conduction electrons [19]. Peaks in the range of 400-600 $\mathrm{cm}^{-1}$ for metal ferrite NPs indicate the presence of a metal-oxygen bond. The splitting of the low-frequency band for the octahedral site (B) reveals the presence of different metal ions including $\mathrm{Fe}^{3+}, \mathrm{Fe}^{2+}$ and $\mathrm{Co}^{2+}$. 


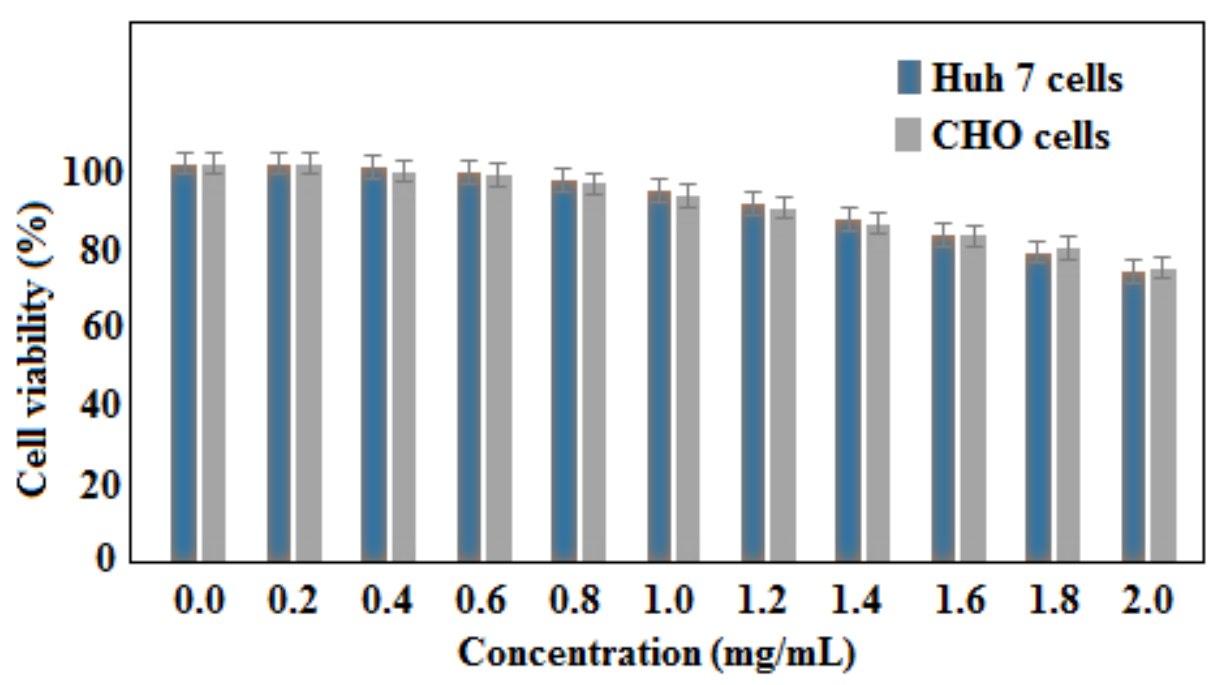

Figure 13: Pharmacological activity of xanthan gum coated $\mathrm{CoFe}_{2} \mathrm{O}_{4} \cdot \mathrm{NPs} @ X G$ against $\mathrm{CHO}$ and Huh 7 cells

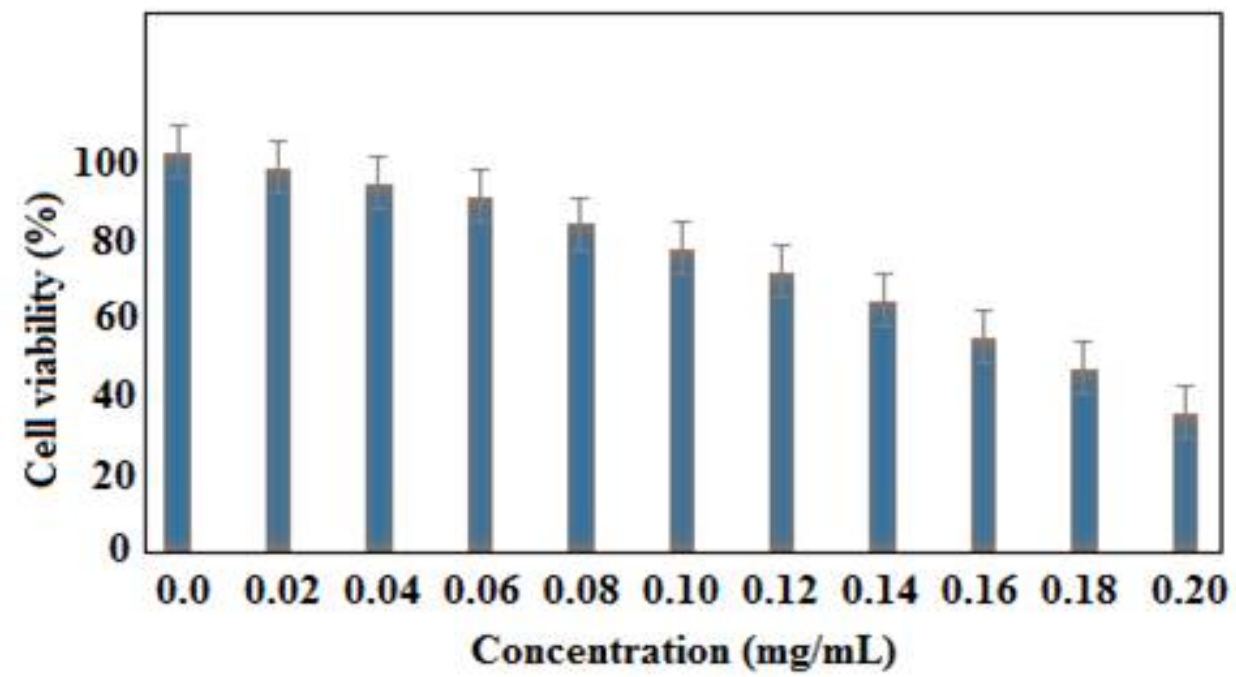

Figure 14: Pharmacological activity of doxorubicin loaded CFNPs (CoFe $\mathrm{O}_{4}$.NPs@XG-Doxo) against Huh 7

However, the slight shifting of the $\mathrm{M}-\mathrm{O}$ peaks of the coated CFNPs was attributed to the polymeric XG layer. The broad absorption band at $3350-3500 \mathrm{~cm}^{-1}$ was assigned to the stretching vibration of the $-\mathrm{OH}$ group. The splitting of the peaks at 2950-3250 and 1547 $\mathrm{cm}^{-1}$ corresponds to the $\mathrm{N}-\mathrm{H}$ stretching and $\mathrm{N}-\mathrm{H}$ bending vibrations, respectively, of the secondary amide group. Briefly, the FT-IR spectrum of the loaded drug (Figure 3c) revealed drug adsorption in two ways: first, by the partial interaction between the $X \mathrm{XG}$ carboxylate $\left(\mathrm{COO}^{-}\right)$and amine $\left(-\mathrm{NH}_{2}\right)$ groups of the drug via amide formation and, second, by the $-\mathrm{OH}$ vibrational bands [21].

The percentage weight loss determined by TGA of the pure CFNPs was attributed to the evaporation of absorbed water and ethanol from the nanoferrite powder surface. Such a small change in mass was consistent with the pure spinel phase of the CFNPs. The mass loss of the XG-coated CFNPs was mostly observed in two regions. The first mass loss was due to the loss of loosely bound water molecules and the coated layer of polymer. However, the second step of a sharp mass loss corresponded to the combustion of the polymer coating from the NP surface [22].

Coating with $X G$ is an effective way to reduce the hydrophobicity of ferrites and increase their water dispersibility. Indeed, the presence of abundant hydroxyl $(-\mathrm{OH})$ and carboxyl $(-\mathrm{COOH})$ groups in $X G$ increases the porosity and surface energy of XG-coated magnetic NPs, and increases their hydrophilicity [23].

The XRD spectra of the native CFNPs $\left(\mathrm{CoFe}_{2} \mathrm{O}_{4}\right.$. NPs) confirmed their crystalline nature with the inverse spinel structure and the space group $\mathrm{Fd} 3 \mathrm{~m}, \mathrm{O}_{h}$. The absence of $h \mathrm{kl}$ planes of iron or cobalt oxides $\left(\mathrm{Fe}_{2} \mathrm{O}_{3}, \mathrm{Fe}_{3} \mathrm{O}_{4}, \mathrm{CoO}\right)$ indicated the purity of the synthesised CFNPs [24]. However, the negligible crystallinity observed for the $\mathrm{CoFe}_{2} \mathrm{O}_{4}$.NPs@XG was caused 
by the amorphous layer of $X G$ that coated the CFNPs.

SEM images of the uncoated CFNPs revealed some agglomeration that was attributed to van der Waals forces and dipole-dipole magnetic attractions [25]. However, the XG-coated CFNPs were less agglomerated and had lower polydespersity.

The absence of a hysteresis loop, and negligible remanence $(\mathrm{Mr})$ and coercivity $(\mathrm{Hc})$ reflected the superparamagnetic behaviour of the CFNPs. The lower Ms value of the coated CFNPs $\left(\mathrm{CoFe} \mathrm{O}_{4} \cdot \mathrm{NPs} @ X \mathrm{XG}\right)$ may be correlated with various factors such as the low mass and small size of the magnetic core and the presence of the magnetically inactive XG layer, which reduced the exchange coupling energy of the magnetic field [26]. Additionally, the high magnetisation value of the native CFNPs reflected their uniform distribution and small degree of agglomeration.

\section{CONCLUSION}

Superparamagnetic nanocrystals of cobalt ferrite has been readily synthesised by co-precipitation with their surface was modified by XG, a foodgrade hydrophilic polymer. Various analyses confirmed the presence of $\mathrm{M}-\mathrm{O}$ bond and bonding of XG functional groups to the surface of the CFNPs. The superparamagnetic behaviour (negligible coercivity, remanence and hysteresis at $300 \mathrm{~K}$ ) of the bare CFNPs is preserved in the XG-coated CFNPs ( $\left.\mathrm{CoFe}_{2} \mathrm{O}_{4} . \mathrm{NPs} @ X \mathrm{XG}\right)$, which suggests its potential as an MNV for anti-cancer drugs. Significantly enhanced release of Doxo from $\mathrm{CoFe}_{2} \mathrm{O}_{4}$.NPs@XG-Doxo in the presence of an AMF has been achieved. The XG-coated CFNPs are biocompatible while the drug-loaded MNV assembly, $\mathrm{CoFe}_{2} \mathrm{O}_{4}$.NPs@XG-Doxo, efficiently inhibits cell viability, which suggests intracellular uptake of Doxo by Huh7 cancer cells. Thus, surface modification of CFNPs with $X G$ is a novel technique to obtain a cytocompatible MNV to deliver Doxo to targeted sites.

\section{DECLARATIONS}

\section{Acknowledgement}

This research was conducted with funding provided by the Higher Education Commission (HEC) of Pakistan. The authors acknowledge the support of Dr Bushra ljaz and other staff members of the Centre of Excellence in Molecular Biology (CEMB), University of the Punjab, Lahore, Pakistan.

\section{Conflict of Interest}

No conflict of interest associated with this work.

\section{Contribution of Authors}

The authors declare that this work was done by the authors named in this article and all liabilities pertaining to claims relating to the content of this article will be borne by them.

\section{Open Access}

This is an Open Access article that uses a funding model which does not charge readers or their institutions for access and distributed under the terms of the Creative Commons Attribution License (http://creativecommons.org/licenses/by/ 4.0) and the Budapest Open Access Initiative (http://www.budapestopenaccessinitiative.org/rea d), which permit unrestricted use, distribution, and reproduction in any medium, provided the original work is properly credited.

\section{REFERENCES}

1. Guo W, Wu L, Chen Z, Boschloo G, Hagfeldt A, Ma T. Highly efficient dye-sensitised solar cells based on nitrogen-doped titania with excellent stability. J. Photochem. Photobiol. A: Chem. 2011; 219: 180-187.

2. Huang J, Zhong $X$, Wang L, Yang L, Mao H. Improving the magnetic resonance imaging contrast and detection methods with engineered magnetic nanoparticles. Theranostics 2012; 2: 86.

3. Yan $C H, X u Z G$, Cheng $F X$, Wang ZM, Sun LD, Liao CS, Jia JT. Nanophased $\mathrm{CoFe}_{2} \mathrm{O}_{4}$ prepared by combustion method. Solid State Commun. 1999; 111: 287-291.

4. Moumen N, Veillet P, Pileni M. Controlled preparation of nanosize cobalt ferrite magnetic particles. J. Magn. Magn. Mater. 1995; 149: 67-71.

5. Ngo AT, Bonville P, Pileni MP. Synthesis and superparamagnetic properties of Nanoparticles. Eur. Phys. J. B - Condensed Matter and Complex Systems 1999; 9: 583-592.

6. Dey S, Ghose J. Synthesis, characterisation and magnetic studies on nanocrystalline $\mathrm{CoO} .2 \mathrm{ZnO} .8 \mathrm{Fe}_{2} \mathrm{O}_{4}$. Mater. Res. Bull. 2003; 38: 1653-1660.

7. Sathaye $S D$, Patil KR, Kulkarni SD, Bakre PP, Pradhan $S D$, Sarwade $B D$, Shintre $S N$. Modification of spin coating method and its application to grow thin films of cobalt ferrite. J. Mater. Sci. 2003; 38: 29-33.

8. Sorescu M, Diamandescu L, Peelamedu, R, Roy R, Yadoji $P$. Structural and magnetic properties of Nisn ferrites prepared by microwave sintering. J. Magn. Magn. Mater. 2004; 279: 195-201.

9. Mathieu A, Lotfi Ben T, Frederic H, Leila S, Francoise V, Nader $Y$, Jean-Marc G, Souad A, Fernand F. Sisedependent magnetic properties of $\mathrm{CoFe}_{2} \mathrm{O}_{4}$

Trop J Pharm Res, July 2017; 16(7): 1673 
nanoparticles prepared in polyol. J. Phys. Condens. Matter 2011; 23: 506001.

10. Davis SS. Biomedical applications of nanotechnologyimplications for drug targeting and gene therapy. Trends Biotechnol. 1997; 15: 217-24.

11. Nappini S, Magnano E, Bondino F, Pis I, Barla A, Fantechi $E$, Pineider $F$, Sangregorio $C$, Vaccari, $L$, Venturelli L. Surface charge and coating of $\mathrm{CoFe}_{2} \mathrm{O}_{4}$ nanoparticles: Evidence of preserved magnetic and electronic properties. J. Phys. Chem. C 2015; 119: 25529-25541.

12. Salunkhe $A B$, Khot VM, Thorat ND, Phadatare MR, Sathish Cl, Dhawale DS, Pawar SH. Polyvinyl alcohol functionalised cobalt ferrite nanoparticles for biomedical applications. Appl. Surf. Sci. 2013; 264: 598-604.

13. Mushtaq MW, Kanwal F, Bashir S, Imran M, Synthesis, Characterisation and biological studies of cobalt ferrite nanoparticles. Bul. Chem. Commun. 2016; 48: 565-570.

14. Akbarzadeh A, Zarghami N, Mikaeili H, Asgari D, Goganian AM, Khiabani HK, Samiei M, Davaran S, Synthesis, characterisation and in vitro evaluation of novel polymer-coated magnetic nanoparticles for controlled delivery of doxorubicin. Nanotechnol. Sci. Appl. 2012; 5: 13-25.

15. Wang G, Ma $Y$, Mu J, Zhang $Z$, Zhang $X$, Zhang L, Che $H$, Bai $Y$, Hou J, Xie $H$. Monodisperse polyvinylpyrrolidone-coated $\mathrm{CoFe}_{2} \mathrm{O}_{4}$ nanoparticles: Synthesis, characterisation and cytotoxicity study. Appl. Surf. Sci. 2016; 365: 114-119.

16. Mahmoudi M, Simchi A, Imani M, Milani AS, Stroeve $P$. Optimal design and characterisation of superparamagnetic iron oxide nanoparticles coated with polyvinyl alcohol for targeted delivery and imaging. $\mathrm{J}$. Phys. Chem. B 2008; 112: 14470-14481.

17. Aronniemi M, Lahtinen J, Hautojarvi P. Characterisation of iron oxide thin films. Surf. Interface Anal. 2004; 36 : 1004-1006.
18. Che E, Wan L, Zhang Y, Zhao Q, Han X, Li J, Liu J, Wang S. Development of phosphonate-terminated magnetic mesoporous silica nanoparticles for $\mathrm{pH}$ controlled release of doxorubicin and improved tumour accumulation. Asian J. Pharm. Sci. 2014; 9: 317-323.

19. Wong HL, Rauth AM, Bendayan R, Manias JL, Ramaswamy M, Liu Z, Erhan SZ, Wu XY. A new polymer-lipid hybrid nanoparticle system increases cytotoxicity of doxorubicin against multidrug-resistant human breast cancer cells. Pharm. Res. 2006; 23: 1574-1585.

20. Arsalani N, Fattahi H, Nazarpoor M, Synthesis and characterisation of PVP-functionalised superparamagnetic $\mathrm{Fe}_{3} \mathrm{O}_{4}$ nanoparticles as an MRI contrast agent. Express Polym. Lett. 2010; 4: 329-338.

21. Zhang Y, Das GK, Xu R, Yang Tan TT. Tb-doped iron oxide: bifunctional fluorescent and magnetic nanocrystals. J. Mater. Chem. 2009; 19: 3696-3703.

22. Liu G, Hong RY, Guo L, Li YG, Li HZ. Preparation, characterisation and MRI application of carboxymethyl dextran coated magnetic nanoparticles. Appl. Surf. Sci. 2011; 257: 6711-6717.

23. Huang Z, Zhu Y, Zhang J, Yin G. Stable biomimetic super hydrophobicity and magnetisation film with Cu-ferrite nanorods. J. Phys. Chem. C 2007; 111: 6821-6825.

24. Khandekar MS, Kambale RC, Patil JY, Kolekar YD, Suryavanshi SS. Effect of calcination temperature on the structural and electrical properties of cobalt ferrite synthesised by combustion method. J. Alloys Compd. 2011; 509: 1861-1865.

25. Zhang $X$, Guo $Q$, Cui $D$. Recent advances in nanotechnology applied to biosensors. Sensors 2009; 9: 1033-1053.

26. Raghavender A. Synthesis and characterisation of cobalt ferrite nanoparticles. Sci. Technol. Arts Res. J. 2014; 2: 1-4. 